\title{
Development and implementation of Strategic Environmental Assessment in Taiwan
}

\author{
Ming-Lone Liou, ${ }^{\mathrm{a}, *}$, Yue-Hwa $\mathrm{Yu}^{\mathrm{b}, 1}$ \\ ${ }^{a}$ Graduate Institute of Environmental Engineering, National Taiwan University, \\ 9F-3, 100, Sec. 2, Hoping E. Rd., Taipei 106, Taiwan, ROC \\ ${ }^{\mathrm{b}}$ Graduate Institute of Environmental Engineering, National Taiwan University, \\ Room 302, No. 71, Chou-Shan Rd., Taipei 106, Taiwan, ROC
}

Received 1 May 2003; received in revised form 1 October 2003; accepted 1 October 2003

\begin{abstract}
Taiwan is one of the few Asian countries to have officially adopted Strategic Environmental Assessment (SEA) as one important means towards the achievement of environmental conservation and sustainable development. Despite implementation almost a decade ago, SEA remains premature in its development. This paper analyzes the progress and characteristics of SEA in Taiwan and, through examination of its limited case studies, reveals the positive and apparent influence of SEA on policy making. This paper also identifies the barriers hindering SEA's advancement and concludes with recommendations on strategies to overcome these obstacles.
\end{abstract}

(C) 2003 Elsevier Inc. All rights reserved.

Keywords: Strategic Environmental Assessment; SEA; EIA; Taiwan; Asia; Sustainable development

\section{Introduction}

Strategic Environmental Assessment (SEA) has evolved in the past decade out of the need for a broader, more comprehensive tool to assess the potential significant adverse environmental impacts of proposed policies, plans, and

* Corresponding author. Tel.: +886-2-2733-4773; fax: +886-2-2733-3293.

E-mail addresses: a4773@ms12.hinet.net (M.-L. Liou), yuehwayu@ccms.ntu.edu.tw (Y.-H. Yu).

${ }^{1}$ Tel.: + 886-2-2363-6104; fax: + 886-2-2362-8043. 
programs (PPPs) early in the decision-making process (Dalal-Clayton and Sadler, 1999; Noble, 2000; Partidário, 1996; Sadler and Verheem, 1996; von Seht, 1999). SEA is a formalized, systematic process that integrates environmental considerations into decision making and aims to achieve sustainable development (Partidário and Moura, 2000; Thérivel et al., 1992; Thérivel and Partidário, 1996). When compared with Environmental Impact Assessment (EIA), SEA tends to be more proactive, accounts for the cumulative effects of environmental problems, and initiates and considers all plausible environmentally sound alternatives (Noble, 2000; Partidário and Clark, 2000). It was also argued that the adaptability and flexibility inherent in SEA is crucial to successful application in different cultural and decision-making environments around the world (Fischer, 2003; Thérivel and Partidário, 1996; Verheem and Tonk, 2000).

Taiwan began preliminary application of EIA on major public works in 1980 . Over 200 projects were implemented with EIA prior to the EIA Act of 1994, the first official piece of legislation to mention SEA. As of the end of September 2003, Taiwan has applied SEA to three cases, and another case is currently under the public consultation process, yet, all differ with respect to their strategic level, scope, and assessment methods/techniques.

Via description of the current status of SEA in Taiwan as well as examination and performance evaluation of its three case studies, this paper illustrates the basic functions and benefits of SEA as applied in the Taiwan context. It also highlights the unique characteristics of Taiwan's SEA system and provides a comparison with international SEA trends.

The concluding sections identify barriers to the full implementation of SEA and recommend ways of overcoming obstacles to the development of a more comprehensive SEA system in Taiwan.

\section{Development and current status of SEA in Taiwan}

\subsection{Legal background and motivation for SEA in Taiwan}

Taiwan is a Newly Industrialized Country (NIC) located on the Pacific Rim of Southeast Asia. About 23 million people inhabit this semitropical island $36,500 \mathrm{~km}^{2}$ in size. Annual per capita income in Taiwan reached US\$13,000 in 2002. In the 1970s, Taiwanese citizens began pressuring the government to invoke environmental quality and conservation measures in response to growing environmental degradation. Such degradation was due to neglect by the government to employ basic pollution control and treatment methods during heavy urbanization and industrialization. In an effort to improve environmental quality, the Taiwanese government implemented various environmental measures, the most important of which was the application of Environmental Impact Assessment. 
In 1980, Taiwan began initial application of EIA on large infrastructure projects, such as dams, highways, harbors, public transportation systems, industrial parks, and power plants, in an effort to prevent further damage to Taiwan's environment. Preliminary application of EIA was confined solely to the project level. Almost 15 years had passed and over 200 EIAs implemented before legislators realized a need to broaden the scope of EIA and introduce SEA into the policy-making system.

SEA first emerged as an official piece of government legislation as Article 26 of the 1994 EIA Act. Article 26 grants authority to EPA Taiwan to devise guidelines, procedures, and manuals for the application of SEA on PPPs with potential significant adverse environmental impacts. In 1997, EPA published SEA Guidelines for Government PPPs. This document:

1. includes SEA procedure (see Fig. 1);

2. states that SEA should be carried out by the competent authority; and

3. requires the content of the SEA Report to include the following:

(a) proposed PPPs and objectives;

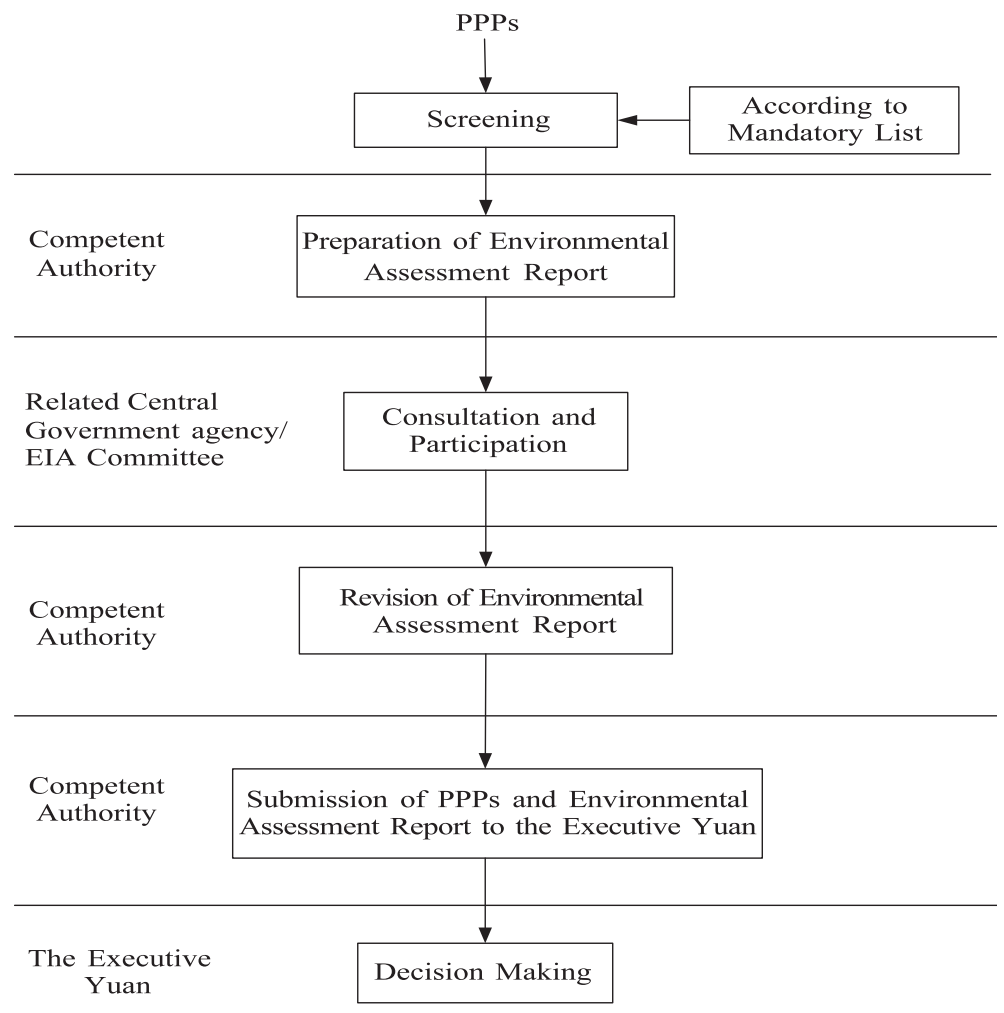

Fig. 1. SEA procedure in Taiwan. 
Table 1

SEA matrix: air quality indicator

\begin{tabular}{lllll}
\hline Indicator and variables & Evaluation & & Mitigation \\
\cline { 2 - 3 } & Local & National & Global & strategies \\
\hline (1) Air quality & & & \\
- Suspended particulates & & & \\
(TSP and $\left.\mathrm{PM}_{10}\right)$ & & & \\
- Sulfur dioxide $\left(\mathrm{SO}_{2}\right)$ & & \\
- Nitrogen dioxide $\left(\mathrm{NO}_{2}\right)$ & & \\
- Ozone $\left(\mathrm{O}_{3}\right)$ & & \\
- Lead $(\mathrm{Pb})$ & & \\
\hline
\end{tabular}

Source: EPA Taiwan, 2001.

(b) background and content of proposed PPPs;

(c) identification and analysis of alternatives;

(d) evaluation of likely significant effects on the environment if the PPP is implemented;

(e) feasible mitigation options; and

(f) conclusion and recommendations.

All PPP documents and the SEA Reports are subject to review by the Executive Yuan ${ }^{2}$ prior to decision making.

One year later in 1998, EPA Taiwan published two important documents: the SEA Manual and the mandatory screening list of PPPs subject to SEA. The SEA Manual (1) requires the employment of a matrix approach for environmental assessment; (2) mandates that environmental impacts should be assessed at three levels, local, national, and global; and (3) establishes preliminary categories of evaluation which comprise of the following eight components: environmental carrying capacity, effect on natural ecosystems, public health and safety, utilization of natural resources, water resource systems and uses, cultural assets and harmony of natural landscape, international environmental treaties, and "others". Each category is given a descriptive guideline ranging from "significantly negative impact (denoted by ' - - ')" to "significantly positive impact (denoted by '++ ')", with " 0 " indicating a neutral effect on the environment. A description of mitigation strategies must be included. Table 1 demonstrates a part of the matrix corresponding to air quality.

The mandatory screening list defines the scope of SEA. It mandates that SEA be applied to those PPPs with potential adverse significant environmental impacts that are included under 9 policy themes incorporating 11 plans/programs as listed in Table 2.

${ }^{2}$ Often referred to as "The Cabinet" in many Western Countries, the Executive Yuan is Taiwan's central governmental authority. 
Table 2

SEA mandatory screening list

\begin{tabular}{ll}
\hline Policy & Plan/program \\
\hline $\begin{array}{l}\text { Industrial } \\
\text { Mineral development } \\
\text { Water resources } \\
\text { development }\end{array}$ & Location of industrial parks \\
Land use & Development and supply of sand/rock \\
& Water resources development and planning \\
& \\
& Development of golf courses \\
& Transformation of land for agricultural uses and \\
& conservation for non-agricultural uses \\
& Reducing the reserving areas for quantity and quality \\
Energy & of water supplies \\
Livestock & Energy structure \\
Transportation & Pig raising \\
Waste management & Railroad and highway infrastructure \\
Radioactive nuclear waste & Household waste management \\
management & Management re-treatment of the nuclear waste \\
\hline
\end{tabular}

Source: EPA Taiwan, 2001.

\subsection{Characteristics and comparative analysis of Taiwan's SEA system}

By 1994, Taiwan had accumulated over 15 years of experience applying EIA to over 200 projects, yet, prior to Article 26 of 1994 EIA Act, there was no public discussion on the feasibility of implementing SEA in Taiwan. Not until the drafting process did legislators decide out of the blue to dually implement SEA and EIA. The 1994 EIA Act reflects the desire to apply EA at a strategic level; however, due to a lack of experience, discussions, and preparations with respect to SEA, the hasty implementation of SEA has presented a great challenge to the government of Taiwan.

Through a detailed study of 20 case studies from both EU and non-EU countries, Sheate et al. (2001) identified four broad models of SEA: (1) EIAinspired SEA; (2) policy analysis/appraisal-inspired SEA; (3) integrationary SEA; and (4) ad hoc mechanisms of environmental integration. Because SEA in Taiwan is generally applied at the plan/program level and has developed incrementally from EIA, the current SEA system in Taiwan can therefore be categorized as close to the model of EIA-inspired SEA.

Based on the works of Gibson (1993), Wood (1995) and Elling (1997), von Seht (1999) established the requirements of a comprehensive SEA system, which consisted of 15 items under the following 7 main categories: legal basis and enforcement, coverage and screening, scoping, assessment and SEA report presentation, participation and publication, final review and decision making, monitoring and auditing.

Through a comparison of Taiwan's SEA system requirements outlined in the SEA Guidelines for Government PPPs, with Von Seht's 15-item requirements, 
Table 3

Main shortcomings of Taiwan's SEA system

Limited PPP coverage

No participation in the screening process

No provisions for scoping

No requirement to prepare a non-technical summary

Lack of provisions for implementation monitoring, impact monitoring, and auditing

No requirement to amend the PPP according to monitoring findings, where appropriate

the main shortcomings (as listed in Table 3) of the current system in Taiwan can be identified. This result indicates that Taiwan's SEA system remains at an early, premature stage of development and is still in progress.

\section{SEA case analyses}

\subsection{Background of SEA cases}

Since implementation of the EIA Act in 1994, a limited number of SEA studies have been undertaken. To date, Taiwan has fully applied SEA to a total of three cases: National Scheme for the Location of Industrial Parks, Construction and Management Guidelines for Golf Courses, and National Water Resources Development Plan. The strategic level, context, scope, and indicators differ for each of these three studies. One ongoing study, the study for Protected Watersheds Reduction Plan is still under the process of public consultation.

\subsubsection{National scheme for the location of industrial parks}

The Industrial Development Bureau of the Ministry of Economic Affairs (MOEA) oversaw the development of a national scheme for the location of industrial parks. This national scheme was designed to spur economic development without sacrificing environmental quality. SEA was applied in order to ease the discrepancy between policy and actual practice exposed in past experience, and was intended to develop more comprehensive guidelines for the siting and construction of industrial parks, with special focus on addressing the following strategic issues: (1) maintain environmental carrying capacity by improving the current permit system; (2) regulate the number, size, and location of industrial parks; and (3) privatize and localize industrial parks.

This SEA study was conducted by SINOTECH Engineering Consultants who completed the SEA Report in November 2000. The Report contains three main parts with the following contents: The first part analyzes the differences between the new and the old industrial park policies; the second part conducts matrix analysis based on indicators provided in the SEA Manual and offers detailed analysis of possible environmental impacts; and the last part provides avoidance or mitigation options for the impacts listed in the previous parts. A matrix 
approach was the main analytical tool used for analyzing environmental impacts in this study. This report has been modified and is currently being reviewed by the Executive Yuan.

\subsubsection{Construction and management guidelines for golf courses}

In the 1990s, about 80 golf courses were already erected on this crowded island. About half of those constructed were deemed illegitimate because of their consequent adverse environmental impacts; some golf course companies also illegally occupied government-owned land. As a result, the government agency responsible for regulating golf courses, the National Council on Physical Fitness and Sports (NCPFS) proposed the design of construction and management guidelines for golf courses. A SEA study was subsequently conducted to address the following strategic issues:

1. coexistence of socioeconomic development and sustainable use of resources;

2. full understanding and acknowledgement of the impacts of golf courses on the environment and ecology of Taiwan; and

3. examination of golf course management policy and institutional arrangements in foreign countries.

The SEA study was conducted by the National Central University which completed the Report in December 2000. It used a different analytical approach than the aforementioned Industrial Park Scheme report. Unlike the previous study which used assigned indicators for evaluation, the indicators used in this study were selected through an ad hoc expert committee, and four evaluation methods (GIS, ad hoc approach, Delphi technique, and AHP) were used for analysis.

Part of the recommendations proposed in this report were adopted by NCFPS and eventually led to the division of Taiwan into four regions, with the number of golf courses in each region capped at carrying capacity for the year 2011. The Executive Yuan also designated NCPFS to normalize the management and development of golf courses and minimize potential environmental impacts.

\subsubsection{National water resources development plan}

To maintain an adequate supply of water resources and ensure water security, the National Water Resources Development Plan was designed as a master plan of guidelines for the conservation and development of Taiwan's water resources, regardless of level (local or regional). The main goal of this plan was to outline a national scheme for land development in order to plan in advance the distribution of water resources for both the short and long term. The national plan was designed flexibly enough to facilitate an ease of revisions when necessary, so as to maintain a balance between supply and demand. A SEA study was conducted for this plan to address the following strategic issues: (1) the current status of water consumption and consumption estimation model for agricultural, industrial, 
and residential sectors at the four watersheds; and (2) mitigation options for various types of dams/reservoirs/weirs construction projects.

This SEA study was conducted by SINOTECH Engineering Consultants who also conducted the industrial park scheme study, and a similar approach based on assigned indicators and matrix evaluation method was used for analysis.

This SEA report was completed in January 2001. Since then, it has been modified, and is still being reviewed by the Executive Yuan at the present time.

\subsection{Performance evaluation of three case studies}

Good practice SEA adds value to the decision-making process by informing decision makers and stakeholders about the sustainability of strategic actions, aiding in the identification of best alternatives, and ensuring a democratic decision-making process (IAIA, 2002; Partidário, 2000). In order to ensure the quality and credibility of SEA, it is necessary to develop a set of evaluation criteria.

Various authors have proposed criteria for good practice SEA. Bonde and Cherp (2000) developed a quality review package which emphasizes that a good quality SEA report should include: sustainability considerations, recommendations on feasible alternatives and mitigation measures, findings resulting from consultation with experts and stakeholders, and difficulties and uncertainties, etc.

Partidário (2000) indicated the priority needs for good practice SEA: ensure accountable decision-making processes; ensure simple, interactive, and flexible approaches; establish an objectives, criteria, and quality standards framework; enable a participatory process; and enable new routines in decision making.

In a "Strategic Environmental Assessment Performance Criteria" article published in 2002, IAIA (2002) proposed that a good quality SEA process is integrated, sustainability-led, focused, accountable, participative, and iterative.

Based on the criteria proposed by the aforementioned authors in this section, and after summing up comments from an ad hoc committee (composed of 33 professors, experts, and government officials) to the three studies, the following findings can be observed with respect to Taiwan's three SEA cases:

1. few or lack of alternatives proposed and considered;

2. failure to inform and/or involve the public during the decision-making process;

3. despite legislation, failure to actually incorporate sustainability in policy making; and

4. minimal and ineffective communication between involved government agencies.

Table 4 provides a more comprehensive performance evaluation of SEA as undertaken in Taiwan. 
Table 4

Performance evaluation of Taiwan's three SEA cases

\begin{tabular}{llll}
\hline Criteria & \multicolumn{2}{l}{ Case } & \\
\cline { 2 - 4 } & $\begin{array}{l}\text { National Scheme for the } \\
\text { Location of Industrial } \\
\end{array}$ & $\begin{array}{l}\text { Parks } \\
\text { Construction and } \\
\text { Management Guidelines } \\
\text { for Golf Courses }\end{array}$ & $\begin{array}{l}\text { National Water } \\
\text { Pesources Development } \\
\text { Plan }\end{array}$ \\
\hline Is integrated & - & + & - \\
Is sustainability-led & $\times$ & + & $\times$ \\
Is focused & - & ++ & + \\
Is accountable & - & + & + \\
Is interdisciplinary & $\times$ & + & + \\
Is participative & $\times$ & $\times$ & $\times$ \\
Is iterative & - & + & + \\
Considers alternatives & -- & + & + \\
Is cost-effective & - & - & - \\
Comprehensive & Poorly organized and & Had organized and & Relatively fair in SEA \\
\multicolumn{1}{c}{ comments } & conducted in few & academically sound & framework, yet not \\
& aspects & approaches & linked to the practices \\
\hline
\end{tabular}

(++) Good; (+) Satisfactory; ( - ) Unsatisfactory; ( - - ) Poor; $(\times)$ Not implemented. Adapted from: Sadler and Verheem (1996); Partidário (2000); Partidário (2002); Bonde and Cherp (2000); IAIA (2002); and EPA Taiwan (2002).

\subsection{The effect of SEA on policy making in Taiwan}

The success of the SEA can be determined in terms of the final outcome and the degree to which the decision was improved as a result of SEA application (Partidário, 2000). Because Taiwan has only applied SEA to a limited number of cases, it is too early to draw meaningful conclusions on the effect of SEA on PPPs. Thus far, we have observed SEA's influence on decision making in only one instance: the Construction and Management Guidelines for Golf Courses.

The SEA Report for this case stipulated the following:

1. Future construction of golf courses should be based on local environmental carrying capacity.

2. No more golf courses will be built in north or central Taiwan before the year 2011.

3. The 23 illegal golf courses currently in existence should be monitored and forced to comply with current regulations.

In November 2002, NCPFS forwarded a bill to the Executive Yuan requesting the cancellation of the ban on golf course development. After soliciting opinions from related agencies, the Executive Yuan mandated that NCPFS must follow the resolutions dictated by the SEA report.

Judging from the adoption of SEA results in this case, it can be concluded that SEA has assessed the impacts of golf courses in Taiwan, provided recommen- 
dations and mitigation options to mitigate impacts, and resulted in some incorporation of environmental considerations in government policy making, which is of relevance to the environmental sustainability of Taiwan. That means the original goal of SEA has been achieved to certain extent in this case.

\section{Problem identification and solving strategies}

Since SEA first emerged in Taiwan, it has been formally applied in only three cases. This reflects the limited experience with incorporating environmental concerns and sustainability principles in decision making in Taiwan. The reason for the relatively slow implementation of SEA in Taiwan was discussed at a SEA workshop on the establishment of SEA methodologies in Taiwan, held by the EPA Taiwan in 2002 (EPA Taiwan, 2002). The workshop participants generalized the reasons for SEA's lagging performance in Taiwan as follows:

1. unfamiliar with SEA procedures and methodologies;

2. lack of understanding with regards to conducting scoping process;

3. lack of or inaccurate Environmental Baseline Data;

4. lack of well-defined and objective quantification measures for assessment or evaluation criteria for use with the mandatory matrix method; and

5. slow implementation speed caused by an unstable political climate.

Based on experience derived from various studies as discussed below and analysis of the three case studies in Taiwan presented in the preceding sections, the following recommendations are proposed by this study to solve the abovementioned difficulties encountered when implementing SEA in Taiwan:

\subsection{Improve the SEA process and include scoping procedures}

A wide range of SEA procedural methodologies are reviewed in the literature (DHV, 1994; European Union, 2001; Sadler and Verheem, 1996; Thérivel, 1996), the majority of which consist of the following steps in order: screening, scoping, impact assessment, review, decision making, implementation, and monitoring.

When compared with this generally accepted process, Taiwan's SEA procedure lacks one fundamental component: scoping. The importance of scoping is to make certain that those issues being discussed during the SEA process are relevant to the decision at hand. In order to save time and reduce costs, Taiwan should incorporate scoping into its current SEA process.

All three completed SEA cases in Taiwan were conducted without a scoping process, as it was not mandated in the SEA Guidelines. Without a properly conducted scoping process, there was no stakeholder consensus on the evaluation indicators/criteria, focus areas, and evaluation/prediction methods for the studies, which makes the follow-up report review process without focus. This is the main 
reason why the SEA reports for industrial park scheme study and the water resources plan study are still being reviewed by the Executive Yuan 2 years after submission.

\subsection{Introduce appropriate methodologies for assessment}

SEA is in itself a family of tools built upon core elements and should be designed as a sufficiently flexible approach (Partidário, 2000). No universal SEA methodology exists, which can be applied uniformly to all strategic actions or in all situations (Thérivel, 2001).

Due to the limited number of case studies and the absence of associated research about SEA methodologies in Taiwan, EPA Taiwan and the competent authorities are unfamiliar with the effective application of SEA concepts to actual practice. This phenomenon constitutes Taiwan's chief barrier to implementing SEA.

This barrier could be overcome by studying and introducing international SEA practices through workshops and training courses, so that EPA Taiwan officials and EA practitioners would be able to adopt and apply those elements, which prove successful to the SEA system of Taiwan.

\subsection{Expand the scope of the mandatory screening list}

Thérivel and Partidário (1996) indicated that SEA can be applied to three main types of actions: sectoral PPPs, area-based or comprehensive PPPs and actions that do not give rise to project but nevertheless have a significant environmental impact.

However, Taiwan's EPA mandated screening list (as shown in Table 2) focuses on two main types of SEA actions only, namely sectoral PPPs and comprehensive PPPs. To increase effectiveness, the mandatory screening list should be expanded to include the third main type of actions, such as WTO accession, comprehensive national development plan, review of regional and urban zoning plan, development of biotechnology (e.g., genetically modified food), export of nuclear waste for treatment, certain legislative proposals, environmental standards (e.g., Effluent Standards), allocation of environmental budget, etc.

\subsection{Increase public participation}

The Rio Declaration (1992) recognizes that public involvement in environmental issues is a prerequisite to ensuring development that supports the principles of sustainability. Sufficient public participation can improve the quality and effectiveness of environmental assessment.

In Taiwan, the participation to SEA process is currently restricted to associated government agencies and the EIA Committee, while public participation in the process is minimal. Therefore, formalized roles for participation by the public 
should be established and maintained, and measures should be taken to encourage participation of all stakeholders.

\subsection{Incorporation of sustainability appraisal in SEA}

As stated in the SEA Guidelines for Government PPPs, the ultimate goal of SEA is to assess the impacts of a policy/plan/program (PPP) on the environmental sustainability of a national/regional/local context in Taiwan. In order to measure the extent of sustainable development in Taiwan, many indicator systems have been designed in the last decade, including those in the "Sustainable Taiwan" and "Sustainable Taipei" projects. Most recently in 2001, the National Science Council of Taiwan proposed the "Evaluation System of Sustainable Development for Taiwan" project, which would develop the first system to be officially accepted by the government. Over 15 national-level departments have been involved in this project to develop detailed variables and obtain corresponding values for the 83 -indicator system. If these indicators can be incorporated into the matrix system for SEA, it will be a major step towards achieving sustainable development in Taiwan. Future research will include the development of a sustainable indicator system for SEA in Taiwan (Liou et al., 2003).

\section{Conclusions}

Even though SEA studies have increasingly become quite common in developed countries, few SEA studies have been conducted in the developing world or newly industrialized countries to date. The few cases that are from developing countries can be found from China (Xiuzhen et al., 2002), Hong Kong, Singapore, Malaysia, the Philippines, Sri Lanka, and Vietnam (Briffett et al., 2003).

Taiwan is one of the few Asian countries to have officially adopted SEA. As if synchronized with the international trend, SEA was formally incorporated as a legal requirement in Taiwan with the EIA Act of 1994, yet remains in a premature development stage with limited application. The major barriers to comprehensive implementation in Taiwan are very much the same barriers hindering broad adoption by the international community, namely insufficient political will, limited societal support base, and bureaucratic prerogatives (Sadler, 1996). Full adoption and implementation of SEA in Taiwan's policy-making system will require greater support from a wide range of stakeholders and achieving the general consensus that SEA does add value to the decision-making process and promotes sustainable development.

In order to expand the application of SEA, we therefore recommend the following activities: (1) organize training programs to educate and familiarize decision makers and SEA administrators about the benefits of SEA and its 
processes; (2) prepare case studies for training purposes; and (3) compare and review Taiwan's system with both similar and dissimilar SEA systems from other countries to learn from the experience of the global community. Due to its unique political environment, Taiwan may be a country often overlooked by the international community, yet, as stated in its Agenda 21(NCSD, 2000), it is fully willing to accept SEA as an essential component of its policy-making system as one crucial step towards achieving sustainable development.

\section{References}

Bonde J, Cherp A. Quality review package for SEA of land-use plans. Impact Assessment and Project Appraisal 2000;18:99-110.

Briffett C, Obbard JP, Mackee J. Towards SEA for the developing nations of Asia. Environmental Impact Assessment Review 2003;23:171-96.

Dalal-Clayton B, Sadler B. Strategic Environmental Assessment: a rapidly evolving approach. In: Donelly A, Dalal-Clayton B, Hughes R, editors. A Directory of Impact Assessment Guidelines. London: International Institute for Environment and Development; 1999. p. 31-42.

DHV Environment and Infrastructure R. Existing Strategic Environmental Assessment methodology; 1994. Compiled for the European Commission DG XI, Brussels.

Elling B. Strategic environmental assessment of national policies: the Danish experience of a full concept assessment. Project Appraisal 1997;12(3):161-72.

Environmental Protection Administration (EPA) Taiwan Homepage, 2001. http://www.epa.gov.tw [accessed 2003].

Environmental Protection Administration (EPA) Taiwan. The establishment of the methodologies of SEA in Taiwan. Taiwan, Dec., 2002.

European Union. Directive 2001/42/EC of the European Parliament and of the Council of 27 June 2001 on the Assessment of the Effects of Certain Plans and Programmes on the Environment. Official Journal of the European Communities 2001;197:30-7.

Fischer B. Strategic Environmental Assessment in post-modern times. Environmental Impact Assessment Review 2003;23:155-70.

Gibson RB. Environmental assessment design: lessons from Canadian experience. The Environmental Professional 1993;15(3):12-24.

IAIA. SEA performance criteria. ND, USA: International Association for Impact Assessment (IAIA); 2002.

Liou ML, Kuo NW, Yu YH. Sustainable indicators for Strategic Environmental Assessment in Taiwan. Paper presented at the Fourth International Conference on Ecosystems and Sustainable Development, Siena, Italy, 4-6 June 2003.

NCSD. Taiwan agenda 21. Taiwan: National Council for Sustainable Development; 2000.

Noble B. Strategic Environmental Assessment: what is it? And what makes it strategic? Journal of Environmental Assessment Policy and Management 2000;2:203-24.

Partidário MR. Strategic Environmental Assessment: key issues emerging from recent practice. Environmental Impact Assessment Review 1996;16:31-55.

Partidário MR. Elements of an SEA framework-improving the added-value of SEA. Environmental Impact Assessment Review 2000;20:647-63.

Partidário MR. Course manual of Strategic Environmental Assessment (SEA). Netherlands: IAIA, 2002. 15-16 June.

Partidário MR, Clark R. Introduction. In: Partidário M, Clark R, editors. Perspectives on Strategic Environmental Assessment. USA: CRC Press; 2000. p. 3-11.

Partidário MR, Moura F. Strategic sustainability appraisal—one way of using SEA in the move toward 
sustainability. In: Partidário M, Clark R, editors. Perspectives on Strategic Environmental Assessment. USA: CRC Press; 2000. p. 29-43.

Rio Declaration on Environment and Development. United Nations Conference on Environment and Development, Rio de Janeiro; 3 -14 June.

Sadler B. Environmental assessment in a changing world: evaluating practice to improve performance Chapter 6 Final Report. International study of the effectiveness of environmental assessment. Australia: Australian EIA Network; 1996.

Sadler B, Verheem R. Strategic Environmental Assessment: status, challenges and future directions. Ministry of Housing, Spatial Planning and the Environment, EIA Commission of the Netherlands; 1996.

Sheate W, Richardson J, Aschemann R, Palerm J, Stephen U. SEA and integration of the environment into strategic decision making. 2001;1-3 (Final Report to the European Commission, London).

Thérivel R. SEA methodology in practice Chapter 3. In: Thérivel R, Partidário M, editors. The practice of Strategic Environmental Assessment. London: Earthscan Publications; 1996. p. $30-44$.

Thérivel R. Distance learning course in Strategic Environmental Assessment. Oxford: School of Planning, Oxford Brookes University; 2001.

Thérivel R, Partidário MR. Introduction. In: Thérivel R, Partidário MR, editors. The practice of Strategic Environmental Assessment. London: Earthscan Publications; 1996. p. 3-14.

Thérivel R, Wilson E, Thompson S, Heaney D, Pritchard D. Strategic Environmental Assessment. London: Earthscan Publications; 1992.

Verheem R, Tonk J. Enhancing effectiveness: Strategic Environmental Assessment: one concept, multiple forms. Impact Assessment and Project Appraisal 2000;18:177-82.

von Seht H. Requirements of a comprehensive Strategic Environmental Assessment system. Landscape and Urban Planning 1999;45:1-14.

Wood C. Environmental Impact Assessment - a Comparative Review. UK: Longman Group Ltd, Harlow, 1995.

Xiuzhen C, Jincheng S, Jinhu W. Strategic Environmental Assessment and its development in China. Environmental Impact Assessment Review 2002;22:101-9.

Ming-Lone LIOU is a $\mathrm{PhD}$ candidate at the Graduate Institute of Environmental Engineering of National Taiwan University. He has participated in research to improve the methodologies of SEA in Taiwan (Dec., 2002). His ongoing research efforts are aimed at the development of a comprehensive SEA system in Taiwan.

Yue-Hwa YU is a Professor at the Graduate Institute of Environmental Engineering of National Taiwan University. His research interests focus on the development of Environmental Impact Assessment and Strategic Environmental Assessment in Taiwan. 